\title{
Prototipe Pendukung Keputusan Pemilihan Saham Jangka Pendek Dengan Kriteria Majemuk
}

\author{
Soetam Rizky Wicaksono, Rudy Setiawan, Purnomo \\ email: soetam.rizky@machung.ac.id, rudy.setiawan@machung.ac.id, pur.nomo@machung.ac.id \\ Fakultas Sains dan Teknologi Universitas Ma Chung
}

\begin{abstract}
Abstrak
Perdagangan dalam bursa efek, khususnya Bursa Efek Indonesia (BEI) telah meningkat pesat, terlebih dalam masa pandemi Covid-19. Volume transaksi telah menunjukkan peningkatan yang cukup pesat dan menjadi justifikasi bahwa perdagangan bursa lebih didominasi oleh transaksi saham jangka pendek. Maka kebutuhan analisis pembelian saham jangka pendek menjadi penting agar risiko kerugian trader dapat diminimalkan. Alat bantu analisis memanfaatkan TA yang disederhanakan agar menjadi pendukung keputusan aksi jual beli. Dalam artikel ini, disajikan hasil dengan menggunakan metode TOPSIS berdasarkan fleksibilitas nilai yang bisa diterapkan pada kriteria secara majemuk. Kriteria yang dipilih merupakan hasil dari wawancara dengan dua trader profesional yaitu posisi candlestick di atas garis EMA, lonjakan volume transaksi perdagangan atau spike volume, kondisi uptrend yang secara otomatis menjadi benefit serta likuiditas dari volume perdagangan. Hasil dari implementasi dengan pembuatan prototipe aplikasi berbasis web menunjukkan hasil yang cukup akurat setelah dilakukan backtest pada akhir September 2021. Namun masih perlu dilakukan backtest dengan periode yang berbeda karena anomali dalam bursa saham Indonesia yang seringkali bersifat volatile. Salah satu keunggulan dari prototipe ini adalah kebebasan untuk pemilihan kriteria dan nilai yang dimasukkan oleh pengguna dibandingkan mayoritas bot yang secara kaku menetapkan kriteria berdasarkan indikator TA.
\end{abstract}

Kata kunci : Pendukung Keputusan, Saham, Trading, TOPSIS

\section{Pendahuluan}

Perdagangan dalam bursa efek, khususnya Bursa Efek Indonesia (BEI) telah meningkat pesat, terlebih dalam masa pandemi Covid-19. Volume transaksi pada tahun 2020 telah menunjukkan peningkatan yang cukup pesat hingga mencapai rekor pada bulan November dengan nilai transaksi di atas $30 \mathrm{~T}$ dalam sehari [1]. Bahkan pada tahun 2021, rata-rata transaksi harian telah mencapai $20 \mathrm{~T}$ yang menunjukkan bahwa ritel di dalam BEI telah menjadi penguasa baru dalam proses transaksi [2].

Data tersebut juga dapat dijadikan justifikasi bahwa perdagangan bursa lebih didominasi oleh transaksi saham jangka pendek dibandingkan dengan investasi jangka panjang. Dengan nilai yang cukup besar dan jumlah ritel yang sangat banyak, hingga mencapai lebih dari 6 juta investor [3], maka kebutuhan akan analisis pembelian saham jangka pendek menjadi semakin penting. Hal tersebut diperlukan agar risiko kerugian para investor jangka pendek (atau lazim disebut sebagai trader), dapat diminimalkan.

Pemilihan saham jangka pendek membutuhkan beragam jenis keilmuan, khususnya analisis teknikal atau Technical Analysis (TA). Sayangnya, pembelajaran tentang TA saat ini dirasa cukup sulit oleh para trader pemula sehingga pada akhirnya mereka terjebak dalam spekulasi serta berita yang mengakibatkan FOMO (Fear of Missing Out) [4], [5].

Demi menghindari risiko tersebut, dibutuhkan sebuah alat bantu untuk para trader pemula secara khusus, agar dapat membantu pada saat mengambil keputusan untuk pembelian ataupun penjualan saham jangka pendek. Alat bantu tersebut secara umum memanfaatkan TA yang disederhanakan sedemikian rupa agar para trader pemula tidak kesulitan dalam mempelajari hal tersebut. Selain itu, alat bantu tersebut diharapkan hanya menjadi pendukung dari keputusan trader untuk melakukan aksi jual beli, sehingga masih dibutuhkan analisis personal mengingat tiap trader dipastikan memiliki style trading sendiri secara privat.

Pendukung keputusan yang sesuai dalam ruang lingkup ini selayaknya menggunakan kriteria majemuk atau multi criteria dikarenakan TA sendiri terdiri dari beragam kriteria yang bisa dipilih dan digunakan dalam beragam kondisi dan situasi perdagangan saham [6]. Pendukung keputusan dengan kriteria majemuk yang secara empiris telah terbukti banyak 
digunakan diantaranya adalah TOPSIS, AHP dan metode lain yang sejenis [7].

Pemilihan metode dalam pendukung keputusan pada dasarnya menjadi sebuah eksperimen dikarenakan tidak ada metode yang sempurna dalam konteks tersebut. Sehingga lebih berdasarkan jenis kriteria yang dipilih serta pemberian nilai kepada tiap kriteria tersebut. Mengingat banyaknya indikator dan kriteria di dalam TA, maka penelitian yang dilakukan dalam ruang lingkup ini terbagi menjadi beberapa bagian dan beberapa upaya eksperimen dengan metode yang berbeda yaitu TOPSIS, AHP dan Promethee. Dalam artikel ini, disajikan hasil dengan menggunakan metode TOPSIS sebagai bagian awal dari rangkaian lingkup penelitian yang lebih besar.

Pemilihan TOPSIS (Technique for Order Preference by Similarity to Ideal Solution) sebagai metode pertama dalam penelitian ini berdasarkan pada fleksibilitas nilai yang bisa diterapkan pada kriteria secara majemuk [8], [9]. Sehingga tiap kriteria dapat diberikan skala yang berbeda. Ini berarti bahwa kriteria yang diberikan dapat tidak memiliki jangkauan yang sama dan sesuai dengan keberagaman dari indikator yang tersedia di dalam TA. Indikator dalam TA sendiri memiliki banyak konsep dan kegunaan yang berbeda yang dapat saling bersinggungan dan juga dapat saling berlawanan satu sama lain. Karenanya, penggunaan TOPSIS layak dilakukan berdasarkan sifat tersebut.

TOPSIS sendiri hingga saat ini telah memiliki lebih dari 4500 sitasi resmi yang menjadikan metode ini selain banyak digunakan juga terbukti secara empiris mampu fleksibel dalam melakukan pemecahan beragam masalah [10]. Dalam penelitian yang sejenis, TOPSIS juga pernah digunakan untuk melakukan prediksi di bursa saham [11], [12], namun pada kasus tersebut lebih terfokus kepada prediksi indeks, bukan pada pemilihan emiten saham seperti yang dilakukan di dalam penelitian ini.

\section{Metode Penelitian}

TOPSIS yang pertama kali diperkenalkan oleh Hwang dan Yoon pada tahun 1981 [7], [9], memiliki dua nilai penting yakni positive ideal solution dan negative ideal solution yang pada akhirnya dapat menentukan rangking prioritas dari alternatif yang telah ditetapkan sebelumnya.

Secara umum TOPSIS diawali dengan langkah memasukkan alternatif, kriteria serta bobot nilai yang didapatkan dari pengguna ahli sebelum dimasukkan ke dalam perhitungan [10], [13]. Selanjutnya dilakukan perhitungan yang melibatkan matriks normalisasi dan normalisasi yang telah terbobot. Kemudian dilakukan perhitungan solusi ideal positif (D+) dan solusi ideal negatif (D-) sehingga menjadi dasar dari perhitungan preferensi [10], [13]. Hasil dari nilai preferensi lalu dapat diurutkan sebagai ranking alternatif yang membantu keputusan dari trader.

Dalam ruang lingkup penelitian ini, alternatif merupakan emiten yang akan dipilih oleh trader berdasarkan screening (filter data berdasarkan transaksi harian, dikarenakan dalam ruang lingkup jangka pendek) awal secara personal. Hasil dari screening tersebut kemudian dipilih sebanyak maksimal empat untuk menjadi alternatif awal.

Kriteria yang dipilih merupakan hasil dari wawancara dengan dua trader profesional yang telah berkecimpung di dunia perdagangan saham jangka pendek setidaknya sepuluh tahun. Sehingga dari kedua orang yang diasumsikan telah mencapai level pakar, dapat menetapkan lima kriteria yang dianggap paling efektif dalam pemilihan saham yang akan dijadikan alternatif.

Sedangkan kriteria yang ditetapkan di awal merupakan indikator TA yang digunakan dalam trading jangka pendek, yang pertama yaitu posisi candlestick di atas garis EMA (Exponential Moving Average) yang dipercaya dapat menetapkan saham dalam posisi uptrend [14]-[16]. Di dalam kriteria ini, EMA yang digunakan untuk penentuan adalah EMA 5, 20 dan 50, dikarenakan asumsi yang jangka pendek dalam perdagangan pada umumnya hanya bertahan dalam waktu kisaran satu hari hingga satu minggu.

Kriteria kedua yang digunakan adalah lonjakan volume transaksi perdagangan atau spike volume yang dapat dideteksi menggunakan frequency analyzer dalam satuan waktu tertentu [17], [18]. Lonjakan volume transaksi yang disertai dengan 
kenaikan harga, dapat menjadi dasar pergerakan harga berikutnya [19]. Sedangkan pada saat lonjakan terjadi dalam kisaran minggu, maka kriteria bisa menjadi valid apabila disertai dengan tren sideways yang konsisten. Namun jika trend dalam kondisi downtrend, maka lonjakan volume bisa jadi dalam kondisi distribusi sehingga menjadi cost dalam perhitungan dan berlawanan jika dalam kondisi uptrend yang secara otomatis menjadi benefit di dalam perhitungan [20]. Sehingga validasi tersebut sekaligus menjadi kriteria ketiga yang ditetapkan.

Kriteria keempat yang diambil adalah likuiditas dari volume perdagangan saham tersebut yang akan dipilih oleh trader. Likuiditas dalam hal ini juga berpengaruh dalam perdagangan jangka pendek , dikarenakan lonjakan volume dapat menjadi indikator palsu bagi sebagian saham yang tidak memiliki likuiditas perdagangan yang konsisten [14]-[16]. Berdasarkan penjabaran yang sudah dijelaskan, maka dapat dirangkum alur pemilihan kriteria dan alternatif dalam diagram berikut:

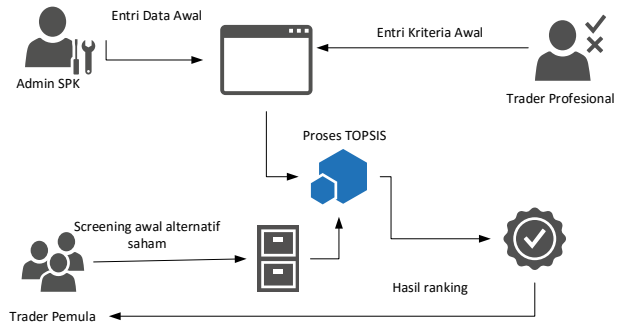

Gambar 1. Workflow Pendukung Keputusan

\section{Hasil dan Pembahasan}

Implementasi dari pendukung keputusan ini dengan menggunakan aplikasi berbasis web bahasa pemrograman PHP dan database MySQL. Sebelumnya perhitungan kriteria disimulasikan terlebih dahulu dengan menggunakan Microsoft Excel untuk cross check dengan hasil implementasi.

Langkah pertama adalah dengan menerapkan data kriteria yang sebelumnya telah dianalisis oleh trader profesional. Hasil analisis tersebut kemudian dibobotkan sesuai dengan kesepakatan awal lalu dimasukkan ke dalam data master kriteria, sehingga hasilnya seperti pada gambar 2 .

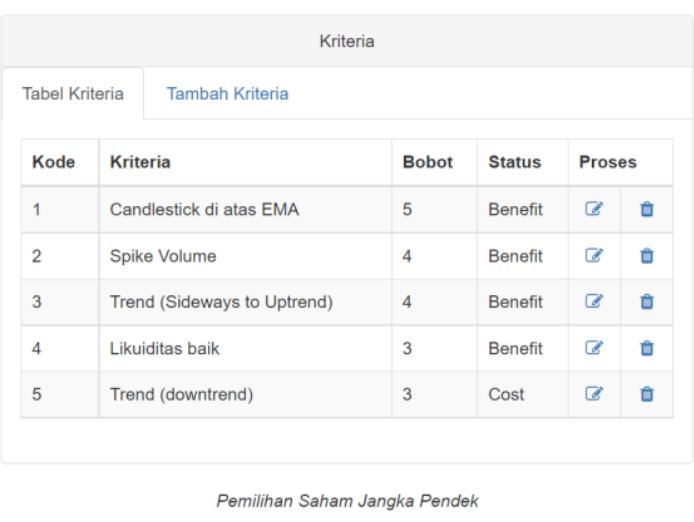

Gambar 2. Data Kriteria Awal

Selanjutnya dimasukkan contoh emiten yang akan dianalisis dalam rangkaian perhitungan TOPSIS. Dalam ujicoba ini dilakukan pada akhir September 2021 dengan mengambil sampling dari empat emiten yang discreeningkan oleh pihak trader profesional untuk melihat hasil dari pemeringkatan alternatif. Pemilihan emiten berdasarkan pada kondisi kenaikan harga pada tiga hari terakhir dan diasumsikan keempatnya memiliki peluang yang sama besar. Hasil dari sampling screening keempat emiten tersebut dapat dilihat pada gambar 3 .

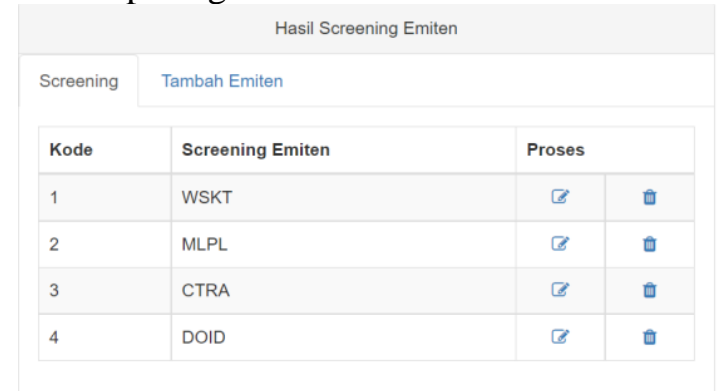

Gambar 3. Data Sampling Emiten

Kemudian, diberikan pemberian nilai dari tiap emiten tersebut untuk kriteria yang telah ditetapkan. Skala dari tiap kriteria sengaja dibuat berbeda agar menjadi pembuktian fleksibilitas TOPSIS dalam melakukan penanganan nilai kriteria majemuk. Untuk kriteria pertama, ditetapkan skala antara $750-1000$, kriteria kedua dengan skala $30-60$, kriteria ketiga dan keempat dengan skala $1-3$.

Langkah berikutnya adalah memberikan hak akses kepada trader profesional untuk menetapkan nilai dari emiten hasil screening yang kemudian dipetakan ke dalam nilai kriteria. Hasil dari 
pemetaan tersebut dapat dilihat pada gambar 4.

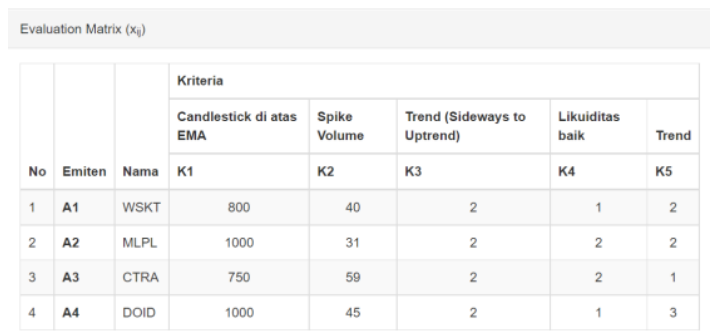

Gambar 4. Pemetaan Nilai Kriteria

Setelah pemetaan nilai dari tiap kriteria selesai dilakukan, maka dapat dilakukan perhitungan dengan menggunakan TOPSIS. Langkah pertama adalah dengan melakukan perhitungan matriks normalisasi dengan rumus :

$$
r_{i j}=\frac{x_{i j}}{\sqrt{\sum_{i=1}^{m} \sum_{j=1}^{n} x_{i j}^{2}}}
$$

Hasil dari matriks ternormalisasi dapat dilihat pada gambar 5 .

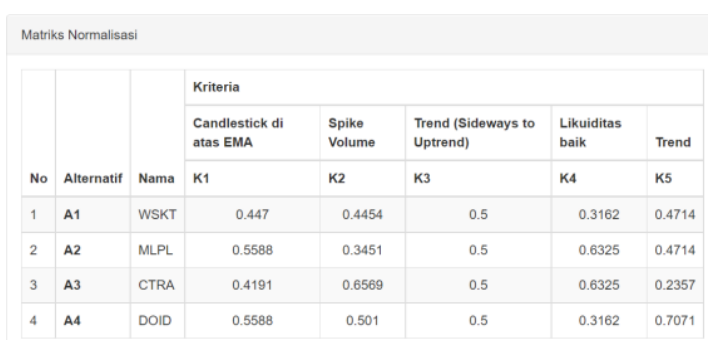

Gambar 5. Matriks Normalisasi

Setelah matriks normalisasi selesai dihitung, maka langkah berikutnya adalah dengan menempatkan bobot pada matriks tersebut agar menjadi matriks yang terbobot. Rumus dari perhitungan matriks adalah :

$$
v_{i j}=w_{i} r_{i j}, i=1, \cdots, m \quad j=1, \cdots, n
$$

..(Rumus 2)

Matriks tersebut menjadi dasar dari perhitungan solusi ideal positif dan solusi ideal negatif. Hasil matriks tampak pada gambar 6.

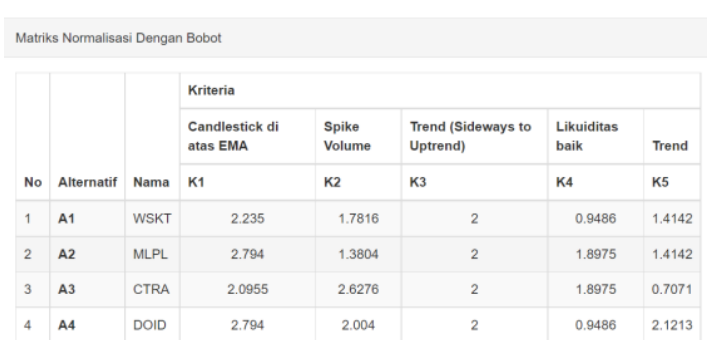

Gambar 6. Matrik Normalisasi dengan Bobot

Selanjutnya, dilakukan perhitungan untuk solusi ideal negatif dan solusi ideal positif. Kedua solusi ini menggambarkan jarak dari tiap kriteria untuk mencapai pengukuran dari tiap alternatif (dalam konteks ini adalah emiten yang dijadikan sampling). Rumus dari perhitungan ini adalah:

$$
\begin{aligned}
A^{+}=\left\{v_{1}^{+}, \cdots, v_{n}^{+}\right\}, \text {where } v_{j}^{+} & =\left\{\max \left(v_{i j}\right) \text { if } j \in J ; \min \left(v_{i j}\right) \text { if } j \in J^{\prime}\right\} \\
A^{-}=\left\{v_{1}^{-}, \cdots, v_{n}^{-}\right\}, \text {where } v_{j}^{*}= & =\left\{\min \left(v_{i j}\right) \text { if } j \in J ; \max \left(v_{i j}\right) \text { if } j \in J^{\prime}\right\} \\
\ldots \ldots \ldots \ldots . . & (\text { Rumus } 3)
\end{aligned}
$$

Sedangkan hasil perhitungan dari tiap solusi, baik negatif maupun positif dapat dilihat hasil screenshot implementasi pada gambar 7 .

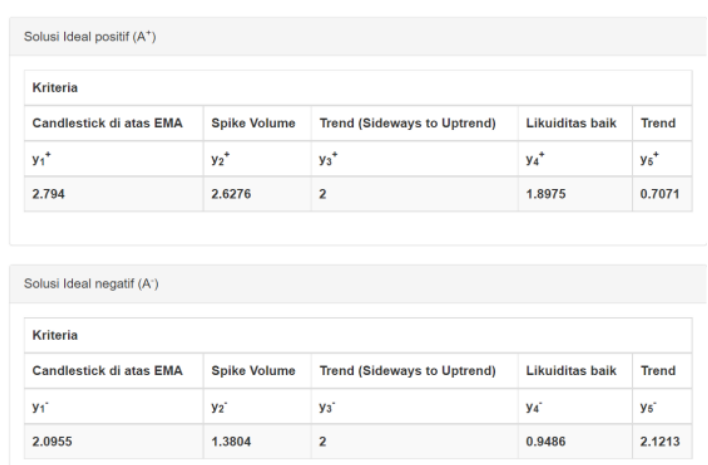

Gambar 7. Solusi Ideal

Hasil dari solusi ideal tersebut kemudian dimasukkan ke dalam perhitungan jarak positif dan negatif. Hasil dari perhitungan jarak tersebut menjadi landasan untuk perhitungan nilai preferensi di langkah terakhir [9], [10]. Rumus dari perhitungan jarak adalah sebagai berikut:

$$
S_{i}^{+}=\sqrt{\sum_{\mathrm{j}=1}^{\mathrm{n}}\left(v_{j}^{+}-v_{i j}\right)^{2}}, S_{i}^{-}=\sqrt{\sum_{\mathrm{j}=1}^{\mathrm{n}}\left(v_{j}^{-}-v_{i j}\right)^{2}}, i=1, \cdots, m
$$

(Rumus 4) 
Sedangkan hasil dari perhitungan jarak positif dan negatif dapat dilihat pada gambar 8 , berdasarkan hasil implementasi di aplikasi web.

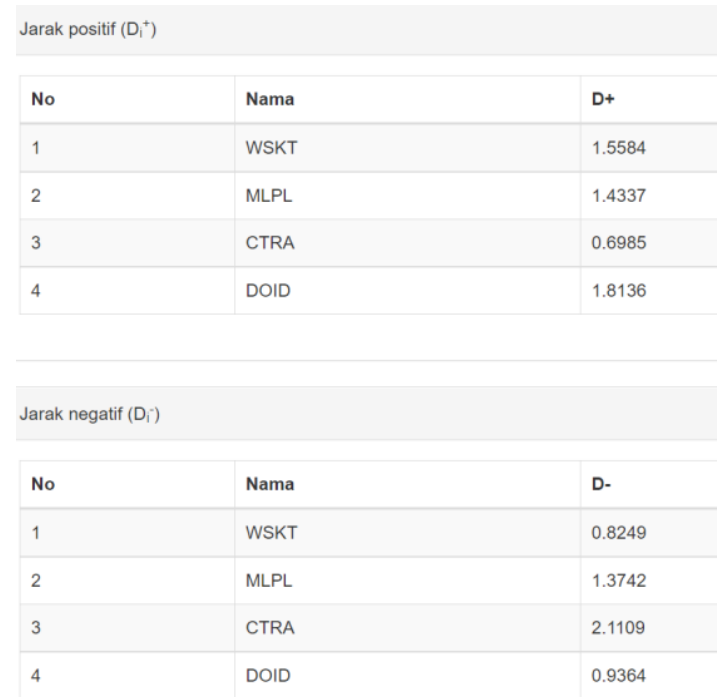

Gambar 8. Hasil Perhitungan Jarak

Langkah terakhir adalah melakukan perhitungan preferensi yang menjadi dasar dari pemeringkatan atau ranking untuk penentuan pemilihan saham yang akan diperdagangkan jangka pendek. Rumus dari perhitungan nilai preferensi adalah sebagai berikut:

$$
C_{i}^{+}=\frac{S_{i}^{-}}{S_{i}^{-}+S_{i}^{+}}, 0<C_{i}^{+}<1, i=1, \cdots, m \ldots(\text { Rumus 5) }
$$

Perhitungan tersebut pada dasarnya merupakan jarak terdekat relatif dari hasil matriks sebelumnya. Sehingga pada hasil yang besar akan menjadi nilai preferensi yang paling dianggap berpeluang untuk diambil keputusannya. Hasil dari perhitungan nilai preferensi di dalam aplikasi dapat dilihat pada gambar 9.

Nilai Preferensi $\left(\mathrm{V}_{\mathrm{i}}\right)$

\begin{tabular}{|l|l|l|}
\hline No & Nama & $\mathbf{V}_{\mathbf{i}}$ \\
\hline 1 & WSKT & 0.3461167289053 \\
\hline 2 & MLPL & 0.48940489333666 \\
\hline 3 & CTRA & 0.75137039937353 \\
\hline 4 & DOID & 0.34050909090909 \\
\hline
\end{tabular}

Gambar 9. Hasil Nilai

Berdasarkan hasil nilai preferensi tersebut, maka didapatkan nilai tertinggi adalah untuk emiten CTRA atau Ciputra
Development Tbk. Sedangkan ranking kedua ditempati oleh MLPL atau Multipolar Tbk. Hal tersebut didasarkan oleh kriteria dari CTRA yang memiliki spike volume cukup tinggi dan dalam trend sideways hingga uptrend. Pada backtest di awal Oktober 2021, dapat dilihat harga berhasil naik cukup signifikan (dari harga 900 ke 950). Hasil uji ini dapat ditelaah pada gambar 10 yang didapat dari bot HQ Saham.

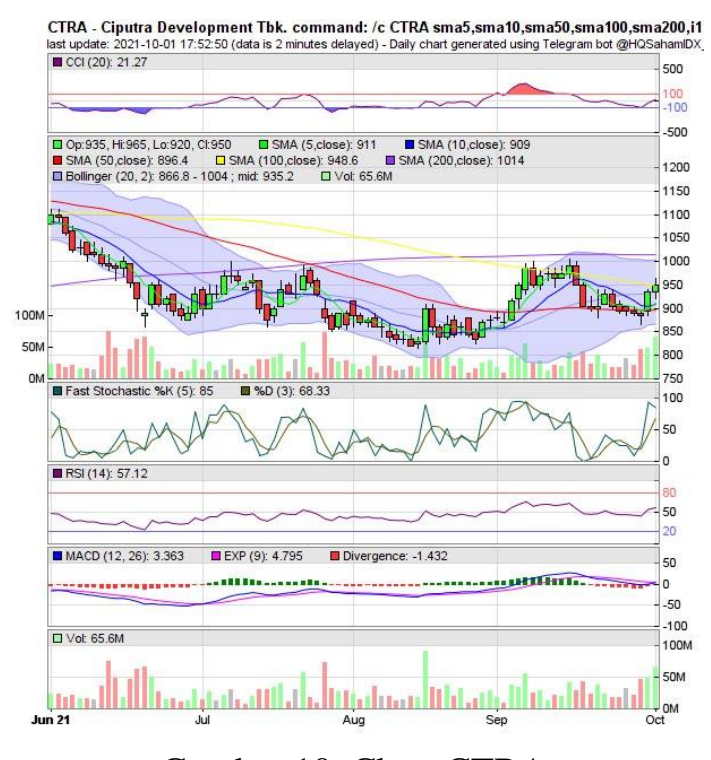

Gambar 10. Chart CTRA

Hasil tersebut kemudian diuji dengan hasil chart spike volume dengan bantuan bot HQ Saham, yang menunjukkan spike volume memang terjadi pada saat sedang dalam kondisi trend sideways hingga uptrend. Hasil uji chart dapat dilihat pada gambar 11 .

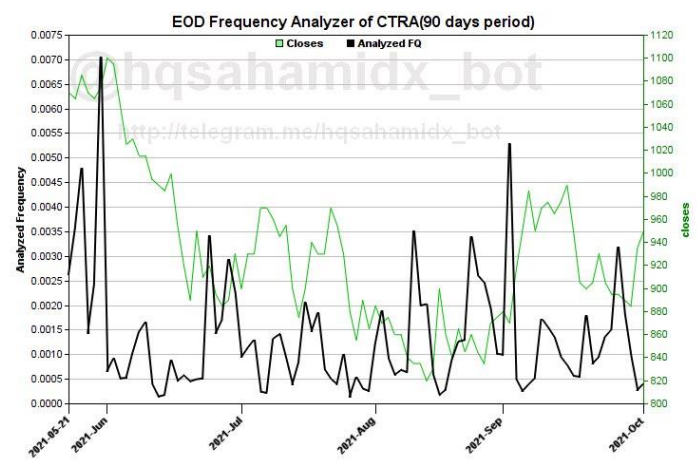

Gambar 11. Spike Volume CTRA

\section{Kesimpulan}

Hasil dari implementasi pemilihan saham jangka pendek dengan menggunakan TOPSIS telah mampu melakukan pemilihan saham jangka pendek. Namun demikian, 
masih perlu dilakukan backtest lebih lanjut dengan periode yang berbeda. Hal ini mengingat kondisi anomali dalam bursa saham Indonesia yang seringkali bersifat volatile dan terpengaruh beragam isu yang sensitif, baik isu politik dalam negeri maupun luar negeri [21].

Selain itu, hasil screening awal emiten yang dijadikan sebagai alternatif awal juga perlu dibuatkan sistem tersendiri agar dapat lebih memudahkan trader pemula dalam memasukkan ke dalam perhitungan. Hasil screening ini bisa jadi dikeluarkan oleh bot ataupun aplikasi saham lain yang mampu melakukan filtering berdasarkan indikator TA tertentu.

Namun demikian, salah satu keunggulan dari pendukung keputusan ini adalah kebebasan untuk pemilihan kriteria dan nilai yang dimasukkan oleh pengguna. Hal ini menjadi nilai lebih dibandingkan mayoritas bot yang secara kaku menetapkan kriteria berdasarkan indikator TA yang sudah ada dalam perhitungan. Padahal tiap trader dipastikan memiliki gaya trading tersendiri yang tidak bisa dipaksakan untuk mengikuti kriteria indikator TA tertentu.

Penelitian selanjutnya, sesuai dengan yang telah dijelaskan di dalam bagian pendahuluan, adalah menguji alternatif dan kriteria yang sama dengan menggunakan metode pendukung keputusan kriteria majemuk lain, seperti AHP ataupun Promethee. Kemudian membandingkan akurasi hasil dengan melakukan backtest dari beragam emiten dan timeframe.

\section{Daftar Pustaka}

[1] M. R. B. Kencana, "Tertinggi Sepanjang Sejarah, Transaksi Harian Saham BEI Capai Rp 32 T di 30 November 2020," Liputan 6, 2020. https://www.liputan6.com/saham/read/ 4422043/tertinggi-sepanjang-sejarahtransaksi-harian-saham-bei-capai-rp32-t-di-30-november-2020 (accessed Jan. 10, 2021).

[2] P. Dorimulu and F. Firdaus, "BEI Catat Transaksi Harian Rp 20,02 Triliun," Investor ID, 2021. https://investor.id/market-andcorporate/bei-catat-transaksi-harian-rp2002-triliun (accessed Jan. 10, 2021).

[3] K. Safitri, "Hingga Agustus 2021, Jumlah Investor Saham Mencapai 2,6
Juta SID,” Kompas, 2021. https://money.kompas.com/read/2021/ 09/02/163651826/hingga-agustus2021-jumlah-investor-sahammencapai-26-jutasid?page=all\#: :text=JAKARTA $\% 2 \mathrm{C}$ KOMPAS.com

Sepanjang,diaktifkannya kembali pasar modal Indonesia. (accessed Jan. 10, 2021).

[4] N. B. Vuong and Y. Suzuki, "Does Fear has Stronger Impact than Confidence on Stock Returns? The Case of Asia-Pacific Developed Markets," Sci. Ann. Econ. Bus., vol. 67, no. 2, pp. 157-175, 2020, doi: 10.47743/saeb-2020-0009.

[5] R. P. Sari and M. R. Maulana, "Sistem Pendukung Keputusan Rekomendasi Emiten Saham Menggunakan Metode Simple Additive Weighting," J. Sist. Komput. dan Inform., vol. 2, no. 3, p. 321, 2021, doi: 10.30865/json.v2i3.3037.

[6] S. Burns and H. Burns, Buy Sell Signals. Stolly Media, 2015.

[7] A. Ishak and Wanli, "Analysis of Fuzzy AHP-TOPSIS Methods in Multi Criteria Decision Making: Literature Review," IOP Conf. Ser. Mater. Sci. Eng., vol. 1003, no. 1, pp. 0-10, 2020, doi:

$10.1088 / 1757-$ 899X/1003/1/012147.

[8] G.-H. Tzeng and J.-J. Huang, Multiple Attribute Decision Making. Chapman and Hall/CRC, 2011.

[9] M. Esfandiari and M. Rizvandi, "An application of TOPSIS method for ranking different strategic planning methodology," Manag. Sci. Lett., vol. 4, no. 7, pp. 1445-1448, 2014, doi: 10.5267/j.msl.2014.6.022.

[10] K. P. Yoon and W. K. Kim, "The behavioral TOPSIS," Expert Syst. Appl., vol. 89, pp. 266-272, 2017, doi: 10.1016/j.eswa.2017.07.045.

[11] R. Dash, S. Samal, R. Rautray, and R. Dash, A TOPSIS approach of ranking classifiers for stock index price movement prediction, vol. 758. Springer Singapore, 2018.

[12] R. Dash, S. Samal, R. Dash, and R. Rautray, "An integrated TOPSIS crow search based classifier ensemble: In application to stock index price 
movement prediction," Appl. Soft Comput. J., vol. 85, p. 105784, 2019, doi: 10.1016/j.asoc.2019.105784.

[13] R. Ewa, "Multi-criteria decision making models by applying the TOPSIS method to crisp and interval data," Mult. Criteria Decis. Mak., no. Mcdm, 2011.

[14] Vezhven, Simple Mix Indicator Analysis. Malang: Seribu Bintang, 2019.

[15] M. Giso, TRIK CUAN. Malang: Litera Mediatama, 2018.

[16] E. Ong, Technical Analysis for Mega Profit. Jakarta: Gramedia Pustaka Utama, 2016.

[17] W. Leigh and R. Purvis, "Implementation and validation of an opportunistic stock market timing heuristic: One-day share volume spike as buy signal," Expert Syst. Appl., vol.
35, no. 4, pp. 1628-1637, 2008, doi: 10.1016/j.eswa.2007.08.063.

[18] J. K. M. Watts, "Language Consistency and Stock Market Trading Volume," SAGE Open, vol. 10, no. 2, 2020 , doi: 10.1177/2158244020919779.

[19] C. Pathirawasam, "The Relationship Between Trading Volume and Jump Processes in Financial Markets," $J$. Compet., vol. 41, no. 3, pp. 41-49, 2011.

[20] P. J. Kaufman, Trading Systems and Methods. Hoboken: John Wiley \& Sons, Inc, 2013.

[21] B. Sutrisno, "Hubungan Volatilitas dan Volume Perdagangan di Bursa Efek Indonesia," Esensi, vol. 7, no. 1, pp. 15-26, 2017, doi: 10.15408/ess.v7i1.3894. 